\title{
AS MARCAS DA ARTE E DA IMAGINAÇÃO PARA UMA FORMAÇÃO HUMANA SENSÍVEL
}

Luciane Maria Schlindwein *

RESUMO: Este texto tem por desafio problematizar o desenvolvimento estético da pessoa (do professor) atravessado pela experiência sensível com as artes em diferentes manifestaçóes. Pautados nos aportes teóricos da Psicologia Histórico-cultural, consideramos que a percepção estética pode se constituir em tema fundante para a formação integral do professor e, em decorrência, das crianças. Discutimos os resultados de uma pesquisa realizada entre os anos de 2004 e 2006, em que um grupo de 12 professoras em formação pôde experienciar vivências artísticas, efetivadas no campo da literatura, das artes visuais e da música. A ampliação de repertório, o desenvolvimento estético e a postura ética constituem-se como decorrências das transformaçóes de sentido, dos processos de tomada de consciência desencadeados pelas vivências estéticas propiciadas aos envolvidos na pesquisa.

Palavras-chave: Percepção estética. Formação de professores. Psicologia histórico-cultural.

* Universidade Federal de Santa Catarina (UFSC), Programa de Pós-graduação em Educação. Florianópolis, SC., Brasil. E-mail de contato: luciane.schlindwein@ufsc.br 


\title{
The marks of art and imagination for a sensible buman formation
}

\begin{abstract}
The challenge of this text is to problematize the aesthetic development of the person (of the teacher), permeated by sense experiences with different manifestations of the arts. Based on the theoretical contributions of the Cultural-historical Psychology, we consider that the aesthetic perception may constitute a foundational theme for the integral formation of the teacher and, as a result, of the children. We discussed the results of a survey conducted between 2004 and 2006 in which a group of twelve teachers in training had artistic experiences, carried out in the field of literature, visual arts and music. The expansion of their repertoire, the aesthetic development and the ethical stand constitute themselves as derivations of the transformations of meaning, of the processes of awareness triggered by aesthetic experiences afforded to those involved in the research.
\end{abstract}

Keywords: Aesthetic perception. Teacher training. Historicalcultural psychology.

As emoçôes da arte são emoçôes inteligentes.

L. S. Vigotski

Se isso faz sentido, pode-se concluir então que o que converte a função natural em cultural e permite que esta apareça naquela é 'o olhar do Outro 'quando ele se torna 'olhar do Eu'.

Angel Pino Sirgado

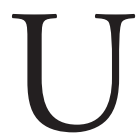

ma das grandes contribuições que Vigotski (1896-1934) nos deixou foi a premissa invertida acerca da compreensão da constituição da humanidade no ser humano. Não basta nascer da espécie humana, homo sapiens, mas é preciso humanizar-se, algo que só se processa em sociedade. Uma sociedade constituída por homens que se forjam em relaçóes que são sociais, culturais e históricas. Muito embora Marx tenha apontado anteriormente o caráter dialético e social que transforma o homem, Vigotski trouxe a discussão para a Psicologia. "Discutir a natureza do social e a maneira como se torna constitutivo de um ser cultural é, sem dúvida alguma, um detalhe muito 
importante da obra de Vigotski, o qual merece uma atenção especial”. (PINO, 2000, p. 47) No texto intitulado: O social e o cultural na obra de Vigotski, Angel Pino dá corpo e forma para o manuscrito escrito por Vigotski em 1929, contribuindo, efetivamente, para compreendermos as bases que sustentam a constituição humana: sua natureza social e seu caráter histórico e cultural.

Ao transformar a natureza o homem se transforma e, como parte integrante desta natureza - premissa básica defendida por Marx -, constitui-se em elemento basilar para a psicologia histórico-cultural. Trata-se de um processo dialético e polissêmico, no qual a palavra tem papel fundante. Não por acaso Vigotski afirma que "[...] a palavra é um microcosmo da consciência humana". Para o autor, a palavra se constitui em uma estrutura aberta, que pode absorver conteúdos os mais diversos, sejam eles intelectuais ou afetivos, de cunho racional ou emocional.

Do ponto de vista semântico, a palavra é constituída pelo significado e sentido. O significado constitui-se em unidade básica na relação que se estabelece entre o pensamento e a linguagem. Trata-se de uma instância mais estável, que garante a comunicação, por exemplo. O sentido, em contrapartida, possui uma dupla composição afetiva: ao mesmo tempo em que provoca emoçóes, é conclamado por elas. De acordo com Vigotski, "[...] o sentido do signo é um processo vivo, confundindo-se com o plano indefinido das ideias, da linguagem interior; em seu estado bruto [o sentido do signo] é sintético [...]". (VIGOTSKI, 2010, p. 224) $\mathrm{O}$ sentido remete-se à forma de pensamento e linguagem interior na consciência de cada pessoa. Agrega-se à face estável representada pelo significado, atribuindo a este, cor, volume, sabor. Desde o seu nascimento, a pessoa humana está em contato com uma cultura, em uma sociedade. Seus sentidos possibilitam perceber o mundo a sua volta.

Para Sanchez-Vasquez, “[...] perceber é entrar em uma relação singular, sensível e imediata com um objeto. [...] A percepção do objeto pôe sempre em jogo o órgão sensorial correspondente do sujeito, mas este só percebe o que é acessível a seus sentidos [...]”. (SANCHEZ-VASQUEZ, 1999, p. 135) O autor nos alerta que a percepção se constitui em experiência psíquica complexa, uma vez que, ao entrar em contato, com o objeto perceptível, na pessoa são evocadas memórias, fantasias, imagens, que despertam reaçóes afetivas. Mas, o mesmo objeto que pode 
despertar surpresa, paixão, alegria, enfim, as mais diferentes reaçóes afetivas, pode se converter em um hábito.

Os hábitos, estruturas ou esquemas perceptivos com os quais, numa determinada sociedade, se organizam os dados sensíveis tendem a converter-se em normas ou regras rotineiras que enfraquecem a capacidade de enriquecer os dados sensíveis com novos significados. A percepção na vida cotidiana tende a repetir-se em esquemas invariáveis e, portanto, automatizar-se. (SANCHEZ-VASQUEZ, 1999, p. 139)

Para Vigotski, o sentido estético é construído na interface entre o objeto estético, a realidade e a possibilidade do homem de atribuir significação. A significação é compreendida como um fenômeno cultural de agrupamentos humanos inseridos em espaços e tempos definidos. E, como atividade coletiva, implica, necessariamente, em acordos. O sentido estético ocupa, portanto, um lugar social estabelecido em um espaço simbólico, significado culturalmente. As concepçóes e os valores subjacentes a estas concepções (BAKHTIN, 2003) são construídos em contextos de significaçáo ao longo das histórias de vida. Ou seja, as interferências de ordem cultural podem desencadear novas formas de significações. De acordo com Pino:

Um componente da tese de Vigotski do "desenvolvimento cultural" (do homem) é a sua capacidade de simbolizar, ou seja, de criar símbolos e significar as coisas. [...] No campo da sensorialidade e da sensibilidade isso se traduz na capacidade de atribuir um sentido - o que equivale a dar significaçóes sociais atribuídas às coisas - às produçôes do imaginário, às imagens formadas como resultado da sensorialidade e ao conjunto das produçóes imaginárias resultantes do remanejamento dessas imagens e da criação de outras novas sem vínculo direto com a percepção sensorial. (PINO, 2006, p. 67-68). 
Ou seja, ao simbolizar, o homem não só se comunica, ele atribui significado ao mundo a sua volta, transformando-o, criando o novo.

O fazer artístico propicia à pessoa um trabalho completo, envolvendo o intelecto, os sentidos, a emoção e os conhecimentos adquiridos - os já construídos e os passíveis de mudanças. Uma educação pautada nas artes propicia o desenvolvimento do pensamento artístico e da percepçáo estética, que caracterizam um modo próprio de ordenar e dar sentido à experiência humana.

O termo desenvolvimento é entendido aqui como um conceito que engloba as transformaçóes que ocorrem nas diferentes funçóes do organismo humano, às quais, mesmo sendo relativamente autônomas, constituem um todo funcional integrado. (PINO, 2005, p. 1930)

A pessoa desenvolve sensibilidade, percepção e imaginação, na medida em que aprecia diferentes manifestaçôes artísticas, atribuindo-lhes significados diversos e podendo, inclusive, transformá-las. (SCHLINDWEIN, 2006)

[...] a arte deflagra o funcionamento de uma rede de funçôes (percepção, linguagem, pensamento, memória, sentimento) que assume o papel de sujeito da recepção da obra: sujeito que suspende temporariamente o julgamento pragmático da vida para vivenciar a fantasia do artista. (TOASSA, 2011, p. 63)

Seguindo estas premissas, consideramos que a própria rotina do professor, inerente ao processo educacional, tende à formação de hábitos, como definido por Sanchez-Vasquez. Assim se produz um congelamento do sentido que pode empobrecer a experiência de ensino e aprendizagem, atingindo professor e alunos e, em outra direçáo, a própria escola. 
O empobrecimento na capacidade de produção de sentido que envolve as paixóes humanas no processo de significação - estanca o simbolizar, o que quebra a cadeia definida por Angel Pino: simbolizar-atribuir significado ao mundo-transformação e criação de um novo mundo.

Considerando assim, que, na escola, o rompimento dos esquemas invariáveis na atribuição de significados - hábitos - implicaria na reativaçáo do processo transformador de desenvolvimento e atribuição de sentido, desenvolvemos uma pesquisa focada na ampliaçáo do universo de sensibilidade dos professores. Considerando, com Bakhtin, que intervençôes culturais podem desencadear novos processos de significação; considerando ainda, com Toassa, que a arte deflagra a percepção, a imaginação e outras funçóes ligadas à atribuição de sentido, a via escolhida foi a de propiciar vivências estéticas junto aos professores envolvidos na pesquisa, no caminho do desenvolvimento do sentido estético que, como definido por Vigotski, se constitui no contato imaginativo e criador com o objeto estético na realidade social.

\section{A PESQUISA}

Entre 2002 e 2004 realizamos uma pesquisa cujo objetivo principal era traçar o perfil social, econômico e cultural dos professores dos anos iniciais do Ensino Fundamental (PINO; SCHLINDWEIN, 2004, 2004b; ZANELLA, 2005) em três redes públicas municipais de ensino.

A pesquisa indicou um perfil profissional surpreendente: professores todos habilitados (grande parte delineou uma carreira acadêmica que inclui o curso magistério em nível médio, superior em Pedagogia e especialização lato-sensu), majoritariamente do sexo feminino ( $99 \%$ dos professores dos anos iniciais e educação infantil) e com uma condição econômica estável (que se destaca em relação aos demais municípios de estados brasileiros). Entretanto, ao confrontarmos os resultados das nossas pesquisas com os índices oficiais de desempenho escolar, percebemos que os resultados apresentados pelo desempenho dos alunos não refletiam a condição de formação e de organização trabalhista dos 
professores. Estes resultados nos moveram a, enquanto grupo de pesquisa, voltar nosso foco de investigação para um trabalho que pudesse mobilizar a imaginação e o ato criador dos professores.

$\mathrm{Na}$ perspectiva histórico-cultural desenvolvida por Vigotski (cujos aportes constituem-se referencial de base da investigaçáo), quanto mais as pessoas ampliam e diversificam suas experiências, maiores as possibilidades de desenvolverem um pensamento mais imaginativo. Para Vigotski (1982) “[...] a imaginação está muito arraigada ao conteúdo de nossa memória”. (VIGOTSKI, 1982, p. 426) Experiência e memória garantem o conteúdo para o pensamento imaginativo. E a imaginação está no cerne da criação humana.

Com o intuito de investir em um repertório mais amplo e diversificado, no que se refere aos bens culturais e artísticos, foram realizadas vivências estéticas com um grupo de doze professoras, entre os anos de 2004 e 2006. As professoras eram alunas regularmente matriculadas no curso de Pedagogia e as atividades aconteceram regularmente, vinculadas a uma disciplina do Curso Pedagogia.

O conteúdo das vivências no primeiro semestre da pesquisa, aconteceu no campo das artes visuais: a história da arte, a mulher na história da arte, a leitura e releitura da obra de arte e o fazer artístico. No segundo semestre, atividades de sensibilização musical foram incluídas. Em 2005, o conteúdo das vivências foi ampliado, incluindo teatro, cinema e literatura. O grupo de formadores (e envolvidos no grupo de pesquisa) estava constituído de artistas plásticos, musicistas, literatos e uma dramaturga. As atividades de vivência propiciaram o envolvimento das alunas/professoras com as diferentes possibilidades de manifestaçóes artísticas. Os encontros foram registrados em vídeo e áudio e, a cada encontro, as alunas/professoras registravam em memoriais, relatando suas percepçóes sobre o vivenciado. Destaca-se o papel importante da escrita dos memoriais: um momento de organização do vivido pela palavra. E, a possibilidade de refletir sobre o vivenciado, atribuindo-lhe significado.

O que se lembra e como se lembra (aspectos da narrativa) são questóes relacionadas ao âmbito social. Dessa maneira, conteúdo (o que) e forma (como) precisam ser investigados em função do impacto que 
produzem no desenvolvimento ontogenético, pois os atos de narrar e lembrar o vivido estão diretamente implicados, no que tange a constituição subjetiva, à forma como nos tornamos humanos, nos apropriamos da experiência alheia e a convertemos em algo que produz sentido pessoal e nos constitui. (SILVA; SILGADO; TAVIRA, 2012, p. 269)

Estudar a memória no homem, então, não é estudar uma "função mnemônica" isolada, mas é estudar os meios, os modos, os recursos criados coletivamente no processo de produção e apropriação da cultura. (SMOLKA, 2000, p. 186)

Ao manterem o vínculo das alunas/professoras com a pesquisa, nas vivências, foi-se configurando uma história coletiva de significados, forjados pela experiência estética propiciada pelo contato com as diferentes manifestaçóes artísticas e culturais (artes visuais, cinema, música, teatro, literatura). As vivências estéticas e momentos de reflexão sobre diferentes manifestaçóes artísticas foram possibilitando o estranhamento, o vivido com o impacto do novo e da ressignificação do que já pudesse estar automatizado, como afirma Sanchez-Vasquez (anteriormente citado). Tínhamos o duplo objetivo de proporcionar uma ampliação de repertório conceitual e cultural das professoras envolvidas e, ainda, pela via da reflexão e auto-reflexão (instrumentalizada especialmente pelos memoriais), criar possibilidades de mobilizar a percepção e a imaginação.

Cabe lembrar que no início da pesquisa, em março de 2004 as envolvidas na pesquisa eram todas alunas do curso Pedagogia, matriculadas regularmente no sexto período do curso. Com a conclusão do curso Pedagogia, em julho de 2005, foram convidadas a continuar na pesquisa. A participação nos semestres seguintes (2005/2, 2006/1 e 2006/2) aconteceu na modalidade de formação continuada, com direito a certificado de formaçáo continuada emitido pela universidade. De acordo com Toassa, 2011,

Nos últimos textos vigotskianos, como nos primeiros, a vivência é campo de conflitos, um verdadeiro entreposto do funcionamento psíquico concreto, lin- 
guagem do impacto vital do meio esterno no sujeito e de sua reação a isso, por meio de uma consciência operante num concerto de funçóes psicológicas que náo pode ser plenamente enquadrada nem nas regulaçóes voluntárias nem nas reaçóes espontâneas (TOASSA, 2011, p. 231)

Vigotski vale-se do termo russo perejivánie que, de acordo com a nota da tradutora, trata-se de um substantivo formado pelo prefixo "pere-" (através) e o verbo “-jit" (viver), o que etimologicamente significa "viver através de", ou seja, da experiência concreta, seja ela real ou imaginária. Mas a "vivência" é mais do que a mera presença na consciência da realidade experimentada, ela envolve um "trabalho mental", consciente ou inconsciente, por parte da pessoa/de atribuição de significação aos elementos do meio que constituem a experiência. Vigotski afirma que uma mesma experiência vivida por duas pessoas provoca tomadas de consciência distintas, de modo que se pode afirmar que a "vivência" de uma experiência envolve, de alguma forma, ter um significado do que ela acarreta: é um trabalho semiótico. Perejivánie não é apenas uma realidade direta à consciência, de seus conteúdos e de suas condiçóes, não é apenas algo experimentado, mas também um trabalho interior, um trabalho mental. (TOASSA, 2011)

\section{AS ANÁLISES}

Os dados coletados, com maior destaque aos memoriais e as análises das gravaçôes em vídeo permitiram a organização de quatro grandes categorias de análise que foram assim nominadas: cognição, afetividade, memória e imaginação.

O foco das análises pautou-se na significação das palavras que congregassem diferentes dimensões humanas: experiências evocadas pela memória; emoçôes e sentimentos produzidos pelos fatos estéticos; ideias e conceitos a respeito de fatos e/ou objetos estéticos, e a produção imaginária gerada por essas três categorias anteriores. 
Na categoria cognição foi incluído o conjunto de conceitos $\boldsymbol{e}$ ideias apresentados pelas professoras, referentes às experiências estéticas vividas (no passado e no presente). Foram incluídos os seguintes indicadores: a) conceitos e ideias existentes a respeito de diferentes produçóes artísticas trabalhadas nas vivências estéticas; b) existência simultânea de ideias e sentimentos a respeito de conteúdos trabalhados nas vivências estéticas; c) identificação dos conceitos e ideias através de indícios (palavras, expressóes etc.).

A categoria afetividade congrega o conjunto das possíveis reaçóes emocionais e dos sentimentos produzidos pelos fatos ou objetos estéticos. Os ambientes das vivências foram organizados em dois grupos: expressóes verbais e expressões não-verbais. Os seguintes indicadores permitiram a organização desta categoria: a) lembranças de emoçóes $\boldsymbol{e}$ sentimentos relacionados com experiências passadas, de caráter estético; b) inexistência de quaisquer tipos de emoçóes ou sentimentos relacionados com experiências passadas, de caráter estético; c) manifestaçóes verbais ou nâo-verbais de emoçóes e sentimentos relacionados com experiências vividas; d) apatia frente às possibilidades de vivências estéticas; e) interesse de participar nas experiências propostas, quando solicitadas à realização de atividades concretas.

A categoria memória foi definida pelo conjunto de experiências vividas (no passado) pelas professoras, nos seus diferentes meios sociais e culturais (referências familiares, do meio social restrito, escolares etc.). Foram considerados os seguintes indicadores, presentes nas expressóes das professoras investigadas: a) qualquer tipo de referências às vivências estéticas do passado (memórias ligadas a vivências anteriores - percebidas, hoje, como experiências positivas ou negativas); b) inexistência de lembranças deste tipo de experiências; c) referências às condiçóes familiares e sociais favoráveis ou não às experiências estéticas (evocadas agora pela experiência vivida no presente).

Analisar a produção imaginária foi um grande desafio para a pesquisa. Entendemos por produção imaginária a produção de imagens e representaçóes imaginárias a partir das experiências vividas nos ateliês.

Ao propormos a imaginação como um elemento presente na dinâmica das vivências/experiências estéticas, precisamos contextualizar 
o seu status na instituição e na formação das professoras, bem como situá-la na perspectiva teórica aqui adotada. Por outro lado, consideramos, na realização das vivências com os professores, que a produção imaginária tem de ser, necessariamente, exteriorizada - seja por palavras, por registros escritos, por desenho ou por açóes - tendo por base a importância do papel da linguagem no desenvolvimento das significaçóes, na perspectiva histórico-cultural. Da mesma forma, importa, ainda, especificar o lugar das emoções no processo de significação das vivências estéticas, além de melhor caracterizar o próprio conceito de vivência empregado nesta pesquisa.

\section{VIVÊNCIAS, EMOÇÕES, IMAGINAÇÃO E LINGUAGEM}

De acordo com Duborgel (1992) a imaginação se configura de forma paradoxal na escola: ao mesmo tempo que se configura como objetivo da formação escolar, a organização dos espaços e tempos no interior da escola impedem ou resistem às manifestaçóes imaginárias que ultrapassem os muros institucionais (sejam físicos ou, muitas vezes também imaginários). $\mathrm{O}$ autor questiona a relação que se estabelece entre imaginação e instituição escolar, em três pontos: a definição de imaginação; se o desenvolvimento da imaginação é indispensável à formação escolar; e, finalmente, se a escola, tal como está estruturada, consegue equilibrar o desenvolvimento da razão e da imaginação.

Para Duborgel (1992), imaginação é, sobretudo, sinônimo de criação, de invenção e de criatividade. De acordo com o autor, um psiquismo imaginativo é ocasionado, do ponto de vista do professor, por um conjunto de sonhos infantis, criativos, naturais e autênticos. Há, entretanto, uma ambivalência neste raciocínio, uma vez que a pedagogia considera a imaginaçáo como um valor ao mesmo tempo essencial e ameaçador (inclusive para a própria estrutura escolar). Se, por um lado, a escola, em seus objetivos mais amplos, pretende desenvolver a imaginação, ela cria formas de cercear, de regular tudo o que escapa, que foge aos padróes esperados de comportamento e aprendizagem definidos em sua própria estrutura. No discurso dos professores, a imaginação se apresenta em dois tempos distintos: um favorável e valorativo, no qual a 
imaginação deve ser incorporada à prática, ao cotidiano escolar; e, quase que simultaneamente, outro tempo, que, pelo uso da racionalidade e em nome de padronizaçóes e conteúdos preestabelecidos, reprime e nega a imaginação na escola. Este dualismo (ou ambivalência) esteve presente em diferentes momentos de nossos ateliês, seja nos depoimentos orais expressos pelas professoras, seja no registro de seus memoriais (que remetem a uma forma mais elaborada e reflexiva de pensamento).

Ainda que a análise das vivências estéticas tenha possibilitado o mapeamento de indicadores referentes a memória, ideias e conceitos, consideramos que o grande motor que é impulsionado pela experiência humana são as emoçóes e sentimentos. Vigotski alerta ao fato de que as emoçóes se constituem em funçóes psicológicas superiores, cujas formas e conexôes biológicas (inferiores) são qualitativamente transformadas. Para o autor, as emoçôes adquirem singularidade como processo psicológico coletivo, forjado nas relaçóes culturais, entre os homens. As emoçóes envolvem a pessoa como um todo, uma vez que sua topologia envolve o sistema nervoso integralmente. Em termos de dinâmica do funcionamento, as emoçóes implicam conflitos, contradições e oposição de sentimentos, provocados pela reação da pessoa frente ao que move a emoção.

A emoção parece possuir a capacidade de selecionar impressóes, ideias e imagens consonantes com o ânimo que nos domina num determinado instante. Qualquer um sabe que vemos as coisas com olhares diferentes conforme estejamos na desgraça ou na alegria. (VIGOTSKI, 2009, p. 25, 26)

As qualidades vivenciais das emoçóes repercutem diretamente na atividade, na consciência e na personalidade da pessoa. Neste sentido, uma formação que propicie a vivência estética provoca o estranhamento, a possibilidade de ressignificação da realidade e do acontecimento.

A alegria, a tristeza, o amor, o ódio, o espanto, o tédio, o orgulho, o cansaço etc. podem se transformar em centros de gravidade que agrupam impressóes ou 
acontecimentos sem relaçóes racionais entre si, mas marcadas com o mesmo signo ou traço emocional. (VIGOTSKI, 2009, p. 27)

Para Vigotski, a consciência é produto das relaçóes e mediaçóes estabelecidas entre o homem e a cultura; é processo contínuo e dinâmico. $\mathrm{O}$ autor considera a pessoa como um ser eminentemente ativo, constituído na relação social com os outros.

A linguagem é o veículo fundamental de transmissão da informação que se formou na história social da humanidade. Ela muda essencialmente os processos de atenção e memória do homem. Mais ainda, a linguagem não serve apenas como meio de comunicação e expressão, mas também como forma de categorização do mundo. O homem percebe e representa o mundo, utilizando categorias de linguagem e esta, por ser produto da prática social é "a arena onde se desenvolve a luta de classes”. (BAKHTIN, 2003, p. 46) A palavra, além de constituir a chave para a compreensão da consciência e da subjetividade, é também espaço privilegiado de criação ideológica. É através da linguagem que se confrontam valores sociais, conflitos, relaçóes de dominação etc.

Portanto, as palavras desempenham um papel central não só no desempenho do pensamento, mas também na evolução histórica da consciência como um todo. "Uma palavra é um microcosmo da consciência humana”. (VIGOTSKI, 1982, p. 132) A transformação do mundo da natureza para o mundo do símbolo se faz pela linguagem. É pela descoberta de que cada coisa tem seu nome, pela significação das palavras que o sujeito vai significando o seu mundo e a si próprio.

"Pela vivência, somos impactados; sofremos a ação da obra de arte, do texto, do quadro. Vivenciar é processo pautado pela imediatidade". (VIGOTSKI, 1998, p. 231) De acordo com Vigotski as vivências conscientes podem ser relativamente sistematizadas e reguladas pela palavra. Pensando a ideia de palavra explanada no Pensamento e Linguagem por Vigotski, como processo em constante mudança e atravessado por tensôes, mesmo com uma relativa sistematização, entretanto, a vivência jamais deixará de ser um campo de conflitos. Assim como uma criança cresce e complexifica tanto seu modo de pensar quanto o de sentir ao 
longo de sua constituição como sujeito, também o próprio conceito de vivência se descortina em vários tipos de facetas na obra de Vigotski. A vivência, então, "assume o status de unidade sistêmica da vida consciente”. (VIGOTSKI, 1998, p. 231)

Termino o trabalho, lembrando as sábias palavras do grande amigo e parceiro nesta pesquisa:

[...] o que é que a cultura faz na natureza do mundo e do próprio homem? Confere-lhe significação, isso que elas não têm e que ao tê-lo não são mais simplesmente o que eram antes. [...] Se isso faz sentido, pode-se concluir então que o que converte a função natural em cultural e permite que esta apareça naquela é o olhar do Outro quando ele se torna olhar do Eu. (PINO, 2005, p. 170-71)

\section{REFERÊNCIAS}

BAKHTIN, M. Estética da criação verbal. São Paulo: Martins Fontes, 2003.

DUBORGEL, B. Imaginaire e Pédagogie. Toulouse: Privat, 1992.

FERrEIRA, A. B. de H. Dicionário Aurélio Básico da Lingua Portuguesa. Rio de Janeiro: Nova Fronteira, 1986.

MARX, K. Manuscritos econômicos e filosóficos e outros escritos. 2a. ed. São Paulo: Abril Cultural, 1978. [Coleção Os Pensadores].

PINO, A. Imaginário e Produção Imaginária: Reflexôes em Educação. In: DA ROS, S.Z.; MAHEIRE, K.; ZANELLA, A.V. (Orgs.). Relaçôes estéticas, atividade criadora e imaginação: sujeitos e (em) experiência. Florianópolis: NUP/CED/ UFSC, 2006.

PINO, A. As Marcas do Humano: as origens da constituição cultural da criança na perspectiva de Lev S. Vigotski. São Paulo: Cortez, 2005.

SANCHEZ-VASQUEZ, A. Convite a Estética. Rio de Janeiro: Civilização Brasileira, 1999.

SCHLINDWEIN, L. M. Formação de Professores, Memória e Imaginação. In: DA ROS, S.Z.; MAHEIRE, K.; ZANELLA, A.V. (Orgs.). Relaçôes estéticas, ati- 
vidade criadora e imaginação: sujeitos e (em) experiência. Florianópolis: NUP/ CED/UFSC, 2006.

SCHLINDWEIN, L. M.; PINO, A. Perfil dos professores das séries iniciais no município de Balneário Camboriú. 2004. Relatório de Pesquisa (PIPG).

SILVA, D. N. H.; SILGADO, A. Pino; TAVIRA, L. V. Memória, Narrativa e Identidade Profissional: analisando memoriais docentes. Cad. Cedes, Campinas, v. 32, n. 88, p. 263-283, set.-dez. 2012.

SMOLKA, A. L. B. A memória em questão: uma perspectiva histórico-cultural. Educ. Soc., Campinas, ano XXI, n. 71, jul. 2000.

TOASSA, G. Emoçóes e vivências em Vigotski. São Paulo: Papirus, 2011.

VIGOTSKI, L. S. A Construção do Pensamento e da Linguagem. São Paulo: Martins Fontes, 2010. . Imaginação e Criação na Infância. São Paulo, Ática, 2009. . Manuscrito de 1929. Educ. Soc., Campinas, ano XXI, n. 71, p. 21-44, jul., 2000. . Psicologia da Arte. São Paulo: Martins Fontes, 1998. . (1933-1934). Aulas sobre pedologia. Iviejsk: Editora da Universidade de Udmursk, 1996. [Tradução de Márcia Pileggi Vinha].

. Obras Escogidas. Madrid, Visor, 1982.

- As bases da pedologia. Leningrado: Editora do Instituto Pedagógico de Leningrado, 1935.

\section{ZANELlA, A. V.; URNAU, L. C.; CABRAL, M. G. Constituiçáo do Sujeito}

e Atividade Criadora: Investigando Professores das Séries Iniciais do Ensino Fundamental em Contextos de Formação Continuada. 2005. (Relatório de pesquisa).

Recebido em 15 de junho de 2015.

Aprovado em 30 de julho de 2015.

DOI: http://dx.doi.org/10.1590/CC0101-32622015V35ESPECIAL154120 